\title{
Stakeholder interactions and the development of functional foods
}

\author{
Aine McConnon ${ }^{1}$, Janet Cade ${ }^{1, *}$ and Alan Pearman ${ }^{2}$ \\ 'Nutrition Epidemiology Group, Nuffield Institute for Health, 71-75 Clarendon Road, University of Leeds, Leeds LS2 \\ 9PL, UK: ${ }^{2}$ Leeds University Business School, Maurice Keyworth Building, University of Leeds, Leeds LS2 9JT, UK
}

Submitted 23 May 2001: Accepted 5 September 2001

\begin{abstract}
Objective: This paper investigates the roles of the individual stakeholders involved in the development of functional foods and the implications of their actions for public perception of this new food concept.

Results: At a time when consumer awareness of the link between diet and health is strong, a new food concept incorporating of a wide spectrum of foods has captured the imagination of the food industry and consumers alike. Functional foods provide a new category of foods that appear to be offering the public the opportunity to achieve a healthy lifestyle with minimal effort. Public perception may determine whether this new food concept is to become the next successful breakthrough in nutritional science or just another marketing gimmick devised by food manufacturers. The paper also addresses issues that arise directly as a result of the emergence of functional foods, such as appropriate legislation in connection to health claims in order to ensure consumer protection and also the lack of clarity in relation to definitions of what constitutes a functional food.

Conclusion: The paper concludes that functional foods can only reach their maximum potential if the food industry, government and health professionals work together to improve communication between themselves and consumers and also to educate consumers, thereby allowing them to make informed decisions about dietary choices.
\end{abstract}

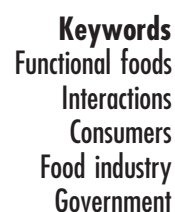

The developing prominence of functional foods has come about at a time when consumer interest in healthy living and diet is at an all-time high ${ }^{1}$. An increase in media coverage on the positive effects of a healthy diet and also an increase in life expectancy have created a public interest in the potential health benefits of such foods offering disease control or prevention ${ }^{2}$. Thinking in the area of nutrition has expanded from the basic need to survive, satisfy hunger and prevent adverse effects to a more advanced emphasis on preventing chronic illness and disease and promoting better health ${ }^{3}$. As a result, the concept of functional foods has spread world-wide, capturing the imaginations of many different groups and individuals ${ }^{1}$. The potential size of the market has attracted interest from and has important implications for a wide range of stakeholders - consumers, governments, the food industry and health professionals.

This new nutritional concept, despite appearing extremely positive and progressive, raises a challenging and wide-ranging set of issues of relevance to nutritionists. Because the concept is a new one there is a great deal of confusion in the area. One main area of confusion, which occurs as a result of the numerous definitions used, is simply what foods are included in this category? By definition, a functional food is one whose effects on the body go beyond usual nutritional effects. The British Nutrition Foundation, for example, defines functional foods as, 'A food having health promoting benefits and/or disease preventing properties over and above its usual nutritional value ${ }^{4}$. However, research has complicated the picture by discovering that certain components of general foodstuffs, such as fruit or meat, may have effects enabling them to be considered to act as functional foods 5 . Functional foods seem to fall into a grey area, somewhere between foods and medicines, with the precise boundaries on either side being far from clear.

The confusion surrounding definition is not simply a theoretical concern. It has significant practical implications. First, there are important legal concerns. The manufacture and sale of foodstuffs are rightly subject to a range of requirements, which vary depending upon the nature of the food and the claims made for it. The various types of functional food, situated somewhere between conventional foodstuffs, health foods and medicines, do not always fit comfortably into the legislation intended to apply to any of these three.

Second, from the viewpoint of nutritional education, the functional foods category does not fit straightforwardly into any of the long-established food educational models, for example the Balance of Good Health ${ }^{5}$. This food 
selection guide was devised with the intention of helping individuals to understand and enjoy healthy eating and is based on the UK Government's eight Guidelines for a Healthy Diet.

Third, and to some extent a consequence of an interaction between the two previous areas of uncertainty, there are concerns relating to consumer perception and acceptability. The experience of recent years has shown how sensitive consumer demand for certain food products can be to public perceptions. In particular, a public perception that associates risk with a given category of food can rapidly undermine demand. Such perceptions need not be in accord with the best available scientific evidence and are readily transferred, again not necessarily with a scientific justification, to other foods that are perceived to be of a similar type. Bad publicity surrounding such food scares as bovine spongiform encephalopathy (BSE) and the use of genetically modified organisms (GMOs) has led to negative consumer perceptions in relation to food safety in general and, in particular, to any foods that seem to be produced in nontraditional ways. However, with appropriate legislation, good scientific support and effective marketing, it is quite possible that any general consumer scepticism can be overcome and, if so, the potential is huge ${ }^{6}$.

The purpose of this paper is to review the key issues surrounding the concept of functional foods and in particular to explore the interactions between the principal stakeholders involved. Beliefs, views and motivations differ among them and, as a consequence, consumers are left in some danger of not knowing what trust to have in functional foods as a whole, or in any one type of functional food. The overall conclusion is that there is a real possibility that the generally confused circumstances within which functional foods are being developed, marketed and consumed will affect their risk perception by society. A clearer understanding among stakeholders of how their respective roles interact is needed to ensure that the potential of functional foods is not dissipated.

\section{Background and definition}

Research on functional foods began in the early 1980s in Japan, where a shift in public focus drew attention towards concern about preventing chronic disease in an ageing population. The term Functional Foods was intended to update terminology associated with fortified foods, to allow for new alleged health claims. Their popularity, established in the 1990s, lies in the expansion of the range of added ingredients and consequently their claimed health benefits ${ }^{7}$. Eighty-six specified research programmes on functional foods were funded by the Japanese Ministry of Education in the early 1980s. Following this, the Ministry of Health and Welfare in Japan approved the term Foods for Specified Health Use (FOSHU) in 1991. Foods in this category are described in Japan's nutrition improvement law as 'foods for special dietary use', foods used to improve people's health and for which claims for specific effects are permitted ${ }^{3}$. Examples of FOSHU approved functional foods include the yoghurts and yoghurt drinks Meji Milk Products, Snow Brand Milk Products and Yakult Honsha. These products contain live lactic acid bacteria. In the USA the Nutrition Labelling and Education Act (NLEA) was enforced in 1994, allowing health claims for foods containing ingredients for which the Food and Drugs Administration (FDA) has scientific evidence showing correlation between intake and prevention or cure of certain diseases $^{8}$. In January 1997 the FDA allowed whole oat foods and also foods containing psyllium to make health claims on reducing the risk of heart disease.

It is important to recognise that cultural differences play an important role in defining functional foods. Ingredients deemed functional in certain parts of the world may be standard in other parts. For example, added lactic acid bacteria that promote the growth of bifidus bacteria in the intestines, regulating them and keeping them in good condition in dairy products would be seen as functional in Europe, but is close to standard in Japan ${ }^{6}$. Furthermore, what are seen as important health issues differ from country to country, with good digestion being the basis of good health in Japan compared with the UK, where lowering cholesterol is a greater concern.

Many different functional food definitions exist throughout the world and vary considerably in length, complexity and content from country to country. Due to the lack of an internationally recognised definition for functional foods and the vagueness associated with the actual concept of functional foods, the differences between functional foods and other superficially similar concepts may be unclear to the public, a factor that has potentially important implications.

Aspects of the functional foods concept are incorporated in a number of other terms. 'Nutraceutical' was first used in 1989 by the Foundation for Innovation in Medicine, to cover 'any substance that may be considered a food or part of a food, and provides medical or health benefits, including the prevention and treatment of disease'. This term was devised to distinguish between functional foods and drugs, implying that therefore functional foods are clearly not drugs ${ }^{2}$. Many functional foods are classified as 'novel foods' and so it is important to clarify this concept also. One definition states that novel foods are 'foods or food ingredients which have not hitherto been used for human consumption to a significant degree, and/or which have been produced by food production processes that result in a significant change in their composition and/or nutritional value, and/or intended use ${ }^{6}$. Foods or food components described as 'novel' may be derived from new plant varieties or from other organisms such as bacteria, yeast, fungi or algae. They may be synthetically produced or derived from a 
genetically modified source 9 . For example, food containing plant sterols (e.g. Flora Pro-activ, Benecol) could be considered as both a nutraceutical and a novel food.

'Health foods' is another concept similar to that of functional foods. Functional foods, however, are ascribed a potency greater than health foods, which are said to be consumed principally for particular nutrient features. 'Health foods' is a marketing rather than a scientific term and describes those products available from specialist retail outlets (i.e. health food shops). Such products typically claim nutrient or health benefits, although in many cases there is little variation in composition from foods sold in mainstream retail outlets ${ }^{10}$. The lack of an internationally recognised definition allows this concept to remain vague.

Functional food definitions have typically been provided by different stakeholders and were put together with different purposes in mind. Many reflect the perceptions of consumers and therefore may be very basic and not very useful as a technical definition, like, for example, that of the International Food Information Council, Washington (1998): 'Foods that may provide health benefits beyond basic nutrition'. Some try to emphasise the point that functional foods are to be consumed as part of the daily diet, for example the Nutritional Food Authority, Australia: '....are intended to be consumed as part of a normal diet ${ }^{, 11}$.

Overall it is clear that a wide range of definitions exists, that they come from different countries, are provided by different stakeholders, were devised with different purposes in mind and are sometimes easy to confuse with definitions of related foodstuffs, such as health foods. This raises questions about the extent to which a consistent understanding exists of exactly what functional foods are and how widely and effectively this understanding is shared. A key factor here is the interacting roles of the different stakeholders involved.

\section{Stakeholders}

Major stakeholders in functional foods include the food industry; both manufacturers and retailers; consumers; the health sector; and governments. Each has different, but strongly interdependent interests.

\section{The food industry}

The success of the food industry is dependent upon product safety, the ability to innovate, and the ability to meet and satisfy consumer requirements. It is clear that the pressure on food manufacturers to innovate is ultimately consumer-driven and failure to respond effectively will mean a loss of both profit and customers ${ }^{12}$. Functional foods are one of the fastest-growing segments in the food industry, among consumers of all ages and health status.

All of the functional foods available on the market today have originated in the disease risk-management phase of nutrition research. An increase in consumer interest in health by means of improving diet has created a niche in the market that functional foods satisfy. The food industry thrives on the knowledge that diet is perceived by consumers as the most important factor contributing to health ${ }^{13}$. The success of the functional food concept is therefore clearly dependent on the food industry's interaction with consumers. In the past, perceptions about healthy eating focused on 'avoidance' of specific food. However, the focus of health promotion is now around change to 'positive eating' ${ }^{12}$, allowing the food industry to successfully improve the potential for healthy eating.

Within Europe, the level of knowledge of their own nutritional intake is poor amongst consumers as a whole with, for example, only $5 \%$ of respondents to a survey carried out in The Netherlands thinking they ate too much fat and only $2 \%$ thinking they ate more fat than average people ${ }^{14}$. This allows certain sectors of the food industry to exploit consumers with great ease. However, with regard to marketing functional foods, the food industry also, contradictorily, relies on consumer knowledge about health risks; for example, marketing foods simply by highlighting their active ingredients. The food industry is enthusiastic about developing new functional foods as these products have added ingredients thus increasing their value, allowing higher prices to be paid for them and returning greater profit ${ }^{15}$. With the knowledge that consumers are believed to be changing their diets to reduce both fat and sugar intake, it may be possible to combine the benefits of functional foods with such desirable characteristics as low sugar and low fat content, extending the impact of functional foods. To do so will require careful management of the food industry's relationship with its different market segment, and an awareness of the role of government and health professionals in setting the nutrition agenda.

\section{Consumers}

From a consumer's point of view the success of functional foods is dependent upon a number of interrelated factors, including concern about general health, accepting responsibility for ability to influence one's own health, and a general awareness of the foods or ingredients that are deemed beneficial ${ }^{16}$. A number of studies published over the last 10 years have illustrated the link between diet and health and have also recognised that consumers are demanding more information on how to achieve better health through their diet ${ }^{17}$, providing a potentially welcoming audience for the introduction of functional foods.

The influence of other newly developed or identified categories of food such as genetically modified (GM) foodstuffs and organic foods will affect how consumers view, and whether or not they will accept, functional foods. Bad publicity surrounding genetic modification has 
arguably led to a significant curtailment of the potential benefits of GM foods, or at least a delay in achieving them. Moreover, the publicity does not necessarily have to relate in any direct or explicit way to the nutritional aspects of GM crops. Although some GM crops are developed specifically for nutritional purposes (for example, golden rice), often the motivation is in terms of improved yields or disease and pest resistance. Nonetheless, negative reactions founded essentially on ethical or precautionary principles, and not necessarily linked to food or any scientific evidence of health damage, are sufficient to induce negative consumer views of GM principles and hence of GM food, and, in turn, lead to diminished enthusiasm from food retailers and government. For many consumers, such negative perceptions may transfer to all new, 'artificial' foods introduced on the market.

On the other hand, consumer concerns in relation to GM foods have in turn increased the popularity of organic foods, which are, generally, perceived as safe 6 . Since organic foods seem to satisfy consumer requirements for healthy foods, it may be difficult for functional foods to compete on a fair nutritional platform ${ }^{6}$. It may be all too easy for consumers to confuse notions of healthiness and safety in relation to organically sourced food with completeness in terms of health and other potential benefits that functional foods may be able to provide.

There may be at least two categories of functional food consumers. The first group, which describes the majority of such consumers, is known as the 'worried well'. This describes individuals who are on the whole healthy, with an adequate diet, and who are primarily interested in prevention of disease in later life. This group may be 'faddy dieters', moving from one trend to another frequently, and thus an unstable source of income for the food industry ${ }^{18}$. Second and more recently, it has been noticed that the ill/diseased are starting to receive a lot of attention from the food industry; for example, people with raised blood cholesterol, heart disease or high blood pressure. Products to improve nutritional status may be appropriately targeted to these groups.

Amongst dietary supplement users there is an inverse supplement hypothesis', in that those more likely to use dietary supplements may be those who least need them ${ }^{19,20}$. This hypothesis may also be true for functional food usage. Those consumers most in need of the added nutrients provided by functional foods, individuals whose nutritional status is poor, may be unable to afford such high-priced commodities, while it is individuals with adequate nutritional intake, who are willing and financially able, who become functional food consumers. However, further study is required to test this hypothesis.

Those in lower socio-economic groups have poorer health, with poor diet playing a role. In a study by James et al., the diets of the lower socio-economic groups were shown to be lower in essential nutrients such as those provided by many functional foods now on the market, for example fortified breakfast cereals containing extra iron and folate and calcium-enriched juices ${ }^{21}$. A healthy diet can cost more than a less healthy one, with fruit and vegetable expenditure being the main items making a healthy diet more expensive. Spending money on food is an independent predictive factor of achieving a particularly healthy $\operatorname{diet}^{22}$. It is probable that functional food consumption will follow the same pattern, since these new foods are, on average, higher in cost than their nonfunctional alternatives. Therefore, we must ask the question, are those who need the extra nutritional advantages offered by functional foods actually those who are consuming them or, due to high prices, are functional foods being made inaccessible to those most likely to benefit from them?

In the case of many functional foods, including fortified foods, it is true that higher levels of nutrients can be provided than are found naturally in some foods. For those who eat limited amounts of food, for example the young, elderly and ill, this may be of benefit ${ }^{23}$. But, is it these groups of people that are consuming such foods? Or is it simply the 'worried well', those individuals whose diet is already nutritionally adequate, consuming such foods? Also, it is important to note that many functional foods may contain a high proportion of a particular nutrient but this may be of little nutritional significance. For example, if intake of the food is likely to be low, if the diet is already more than adequate for that particular nutrient, or if other components in the food or diet are likely to reduce the nutrient's bioavailability?.

\section{Health sector}

Increasingly, consumers are turning to scientists and health professionals to clarify the precise role that foods have in maintaining and promoting health ${ }^{24}$. This, along with a consumer tendency to trust the medical profession, illustrates just how important it is that manufacturers present this new category of foods as an opportunity to 'optimise nutrition' rather than a way of endorsing good or bad foods, or as a marketing gimmick ${ }^{24}$. A study carried out by Morris et al. in 1999 revealed that the majority of general practitioners (GPs) surveyed (89.6\%) agreed that nutrition plays an important role in disease management and $82.4 \%$ agreed that they can offer healthy eating advice to patients ${ }^{25}$. However, it is interesting to note that GPs do not discuss nutrition in consultations as often as they could and the major barriers include lack of nutrition training and education in medical schools. Possible developments to increase nutritional information given to consumers by health professionals are to increase the number of dietitians working with family physicians and nutrition training for practice nurses, as well as making more specific information available to $\mathrm{GPs}^{26}$.

A shift in priorities in the marketing of many functional foods towards health professionals indicates manufacturers' efforts to concentrate on promoting functional 
foods to the more stable market of illness treatment Increasing evidence that preventative measures should be implemented at an early stage in life has caused an increase in the establishment of comprehensive strategies for promoting health ${ }^{27}$, increasing the potential for functional foods. Also, nutritionists' role in educating consumers highlights the importance of targeting nutritionists for the success of functional foods.

\section{Government}

Functional food industry growth in Europe is greatly affected by the lack of specific laws in place. At the 'Functional Foods - Claims and Evidence' conference held in April 1999, the view was expressed that the law regarding functional foods was too restrictive and that changes were required in order to improve flexibility, as exist in other nations ${ }^{4}$. The British Government has failed to regulate functional foods, instead leaving it up to the other stakeholders involved to develop a voluntary $\operatorname{code}^{28}$. Recently the need for appropriate regulation over health claims by food products has been recognised within the UK. In December 2000, after three years of deliberation, the Joint Health Claims Initiative (JHCI) launched its Code of Practice ${ }^{29}$. It is believed that this voluntary code will provide protection for consumers and the food industry alike; however, it has only been implemented on a voluntary basis. It has been suggested that 'support dossiers' should be prepared by industry so that all of the evidence concerning the effect of the food on function and disease risk can be assessed ${ }^{30}$.

Government advice in the UK for a reduction in fat content in the diet may be a major driving force for changes in food composition. However this can lead to consequent changes in the sugar or fibre content of products, which may still be sold on their virtues as low-fat products, with no reference being made to the other changes. It is important that the government ensures that functional ingredients are safe, that labelling and advertising claims are adequately substantiated, and that health claims are not used to divert attention from negative features of products. After consultation with all stakeholders, there is a strong argument that governments should seek to establish adequate regulation controls in order to achieve those objectives ${ }^{31}$. Poor understanding and lack of communication between the different stakeholders with regard to functional foods may well go a long way towards explaining why there may be many different definitions and perceptions of functional foods.

A further dimension to government intervention is the international one, especially from the UK perspective: the need for coherent policy throughout the European Union (EU). Cultural and ethnic differences between countries as well as different interpretation of health claims make generalisation of functional food developments difficult and further complicate issues. Approaches taken by government and industry differ between countries and may be failing to protect consumers from dubious health claims and poorly tested ingredients ${ }^{31}$. For example, allowing a food to be marketed in such a way that it is easy for the consumer to mistakenly believe that it is a functional food. However, for appropriate legislation to be implemented within the EU, there is a need for shared and specific understanding of functional foods. This is likely to be an extremely demanding task due to interaction between two causes of confusion: genuine difficulty in establishing what a functional food is and multiple viewpoints between stakeholders and countries.

There is an obvious lack of legislation in the functional foods sector. Medicinal claims on foods are specifically prohibited. However health-promoting rather than disease-preventing claims are allowed, provided the claim is scientifically proven and not misleading for consumers. Such restrictions in legislation are said to act as the primary barrier to market development in the functional foods sector. In contrast, too much latitude could result in poorly researched claims filtering through and diluting the authority of genuine functional breakthroughs and undermining prospects of long-term growth'6. A major dilemma facing the regulation of functional foods is that they exist at the interface between foods and drugs ${ }^{32}$. In almost every country in the world there are separate laws for dealing with medicines and foods. Countries differ in how they define medicines and foods, so problems arise when manufacturers want to make specific claims about their products ${ }^{33}$. Although the concept of functional foods has been the focus of discussions for many years within the member states of the EU, so far no common position has been reached on either the scientific or regulatory aspects $^{34}$.

\section{Interactions between the stakeholders}

Figure 1 illustrates schematically how the future of functional foods may be seen as critically dependent upon good communication and trust between stakeholders and how misperception can threaten to undermine its potential. The model draws on Yardley et al.'s (1997) work on the social construction of risk ${ }^{35}$. Risk is an important concept and viewed differently by the various stakeholders. The model serves to link together many of the issues outlined in the previous two sections.

A starting point for interpreting Fig. 1 is on the left-hand side, where technical assessment identifies the potential health and nutritional benefits of a functional food or a new class of functional foods. Pinpointing the component of the diet that has a health-promoting effect is a particularly difficult process. It requires collaboration between the food industry and health sector academics to carry out high-quality impartial research. However, moving clockwise, whether development can successfully take place will depend most directly on whether the balance of benefits over risks, as perceived by individual 


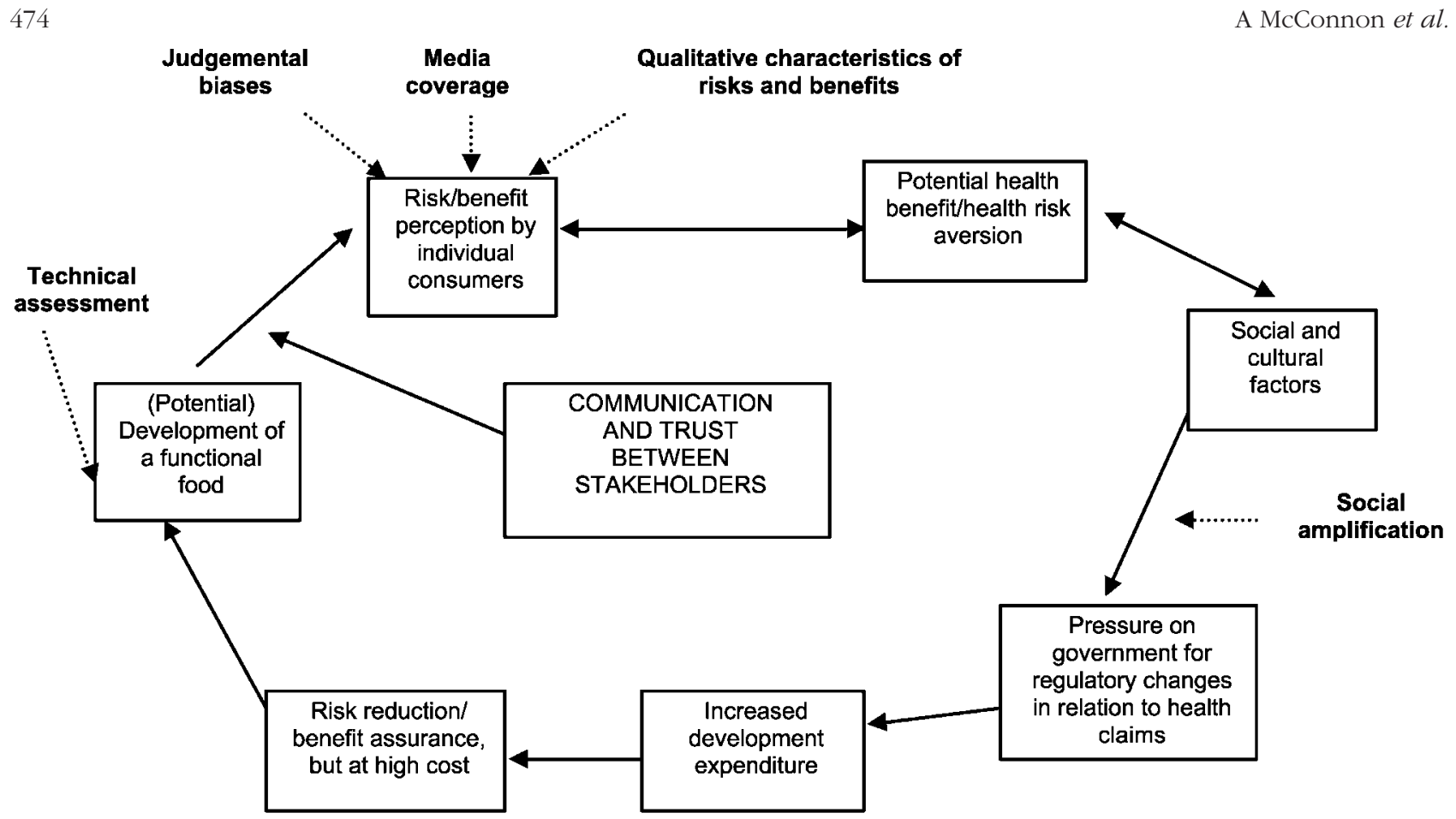

Fig. 1 Interaction of the stakeholders involved in functional food development

consumers, is significantly positive relative to cost and in the light of alternatives. It is important to recognise that, in addition to the influence of the market, consumers' perceptions and, to some extent, the perceptions of the other stakeholder groups are relevant.

Negative perception that food manufacturers are little more than big food factories with anything but consumers' health issues at heart does not help the situation ${ }^{36}$. When consumers were asked whether they agreed or disagreed with the statement: 'A lot of health claims made by food manufacturers about their products are misleading', 78\% of respondents agreed, with more than half of them agreeing strongly. Such cynicism gives an idea of the tough obstacle limiting the success of functional foods for the food industry ${ }^{6}$. Thus it is clear that the potential success of functional foods depends in no small part on the ability of the food-manufacturing sector to successfully manage its relationships with consumers and other stakeholders.

Consumers' perceptions of risks and benefits, moreover, are not determined simply by the scientific 'facts'. How they are presented and who they are presented by are important, as is the context within which the presentation of information takes place and has taken place in the past. Kunreuther and Slovic (1996) have argued that the lay public sees life as increasingly risky, whereas experts believe the opposite (an example of what could be seen as a judgemental bias) ${ }^{37}$. Slovic et al. (1980) were among the first to show how people construct an understanding of risk that is qualitatively quite different from scientific risk assessments, a finding that has been reproduced on a number of occasions since ${ }^{38}$. Communication about risks and benefits to consumers is usually in terms of media coverage, but may be directly from government or from industry sources. Clear wording of health claims is also important for successful communication between marketing, consumers and government regulators.

Moving to the top right-hand corner of Fig. 1, the collective view of individual consumers about the risk/benefit balance is an important initial influence on the potential of a functional food. However, in addition to the psychological factors that may intervene to affect this judgement, two further, social, influences exist. First, as has been set out earlier, different national, ethnic or social groups are known to have different attitudes to nutritional issues. Thus social and cultural factors need to be taken into account, anticipating potentially different responses from different sections of society. Second, if the health claims or other factors associated with a functional food become disputed, there is the real possibility that concerns may be amplified, notably through media coverage but also because of the qualitative nature of any risks that might be highlighted in the debate.

Such social amplification (e.g. Kasperson and Kasperson $^{39}$ ) may be particularly likely if key stakeholders are seen to be at odds with each other. For functional foods to be successful, manufacturers must clearly demonstrate that their products are safe for their intended use. Any medical claims must be substantiated by well-documented scientific evidence ${ }^{2}$. Thus interactions with nutritionists and other key health sector stakeholders are central. Government support of the emerging functional food 
concept is also important and will be aided if there is evidence available that consumption of functional foods may contribute to reduction in health service costs.

Conversely, amplification of public disagreement between stakeholders could induce pressures on government for more rigorous regulation to allay public fears. This in turn might well lead to significantly increased development expenditures (bottom of Fig. 1), paralleling the frequently argued view that many industries have been forced into excessive responses to risk in the light of public disagreement about the true risks associated with their activities (e.g. the construction industry following Ronan Point, the rail industry after Clapham, the offshore oil industry after Piper Alpha).

At present, there are no specific Government or other guidelines relating to functional foods, although existing food laws do serve to prevent misleading health or medical claims on products and so may to some extent restrict the products that can be developed by the food industry. Of more concern from an industry perspective may be the possibility that functional foods may have to be tested as rigorously as drugs. This could have particularly negative consequences for the smaller companies in the food sector. Functional food manufacturers also need to capture the attention of the medical profession, as the food industry is aware that consumers seek advice from and trust the medical profession.

From the consumer perception viewpoint that underlies so much of the relationship between the food industry and consumer stakeholder groups, it is interesting to reflect on the very notion of functional foods and to return briefly to the question of definition. While the three professional stakeholder groups (industry, health sector and government) may debate how functional foods should be delineated, the extent to which the idea of functional foods is either known or understood by the general public is questionable. More likely, the public relates more closely to individual types of functional food (cholesterolreducing spreads, for example) and/or to health concerns that may be addressed by functional foods (digestion problems). Attempts to frame public debate, advertising or even legislation in terms of 'functional food' as such, may well have little success and may indeed be counterproductive if concerns about some types of functional food influence debate and legislation about the whole group.

It is also important to recognise that consumers, too, are far from being a homogeneous stakeholder group. In considering interactions between stakeholder groups, it is important to factor into the analysis this variety. For example, while some consumers are both willing and able, in financial and educational terms, actively to pursue health goals, others, often those most in need of the added benefits this new group of foods claim to have, are not. If functional foods provide potential help to this latter group but at the risk of threatening to 'functionalise' the food of an articulate and influential group, who may not want or need their food to be treated in this way, where does the balance of rights lie? Are there practical compromises?

In relation to legislation regarding health claims, the Nutrition Labelling and Education Act of 1990 allowed health or disease prevention claims on food labels for the first time. A health claim is defined as 'any substance that expressly or by implication characterises the relationship of any substance to a disease or health-related condition'. However, model health claims approved by the FDA are far from consumer-friendly and fail in their intentions of communicating better to consumers the actual effects of their diet on their health ${ }^{32}$. A survey carried out in 1995 by the Consumers' Association in the UK revealed that $84 \%$ of consumers agreed that health messages and nutrition claims on foods should be regulated. This shows how consumers rely on the government to protect them from any misleading claims. However, this simple request for protection may be made more difficult by poor communication between stakeholder groups. Scientific substantiation of the claims using valid methods is important to contribute to consumer education ${ }^{30}$.

Despite some clear opportunities for effective collaboration between health professionals and the food industry, it should be recognised that there are potential pitfalls. Much of the potential arises through the trust accorded to health professionals. There is a very fine balance that needs to be struck, however, between general advice on nutrition and the potential contribution of functional foods and inappropriate promotion of particular functional food brands. If health professionals overstep the mark, trust in them as a source of information may be lost and could prove difficult to re-establish. There are also difficult questions of practicality to be addressed in terms of effectively improving diet. For example, what attitude should be taken to nutritionally poor-quality functional foods, such as functional confectionery? Are such things an appropriate target for legislation, or should they be left to individual choice, supported by professional advice? Issues such as these again serve to highlight the complex interdependencies between the four main stakeholder groups. The final interpretation to be drawn from Fig. 1 is that, if food manufacturers and professionals wish to create the most supportive circumstances for functional foods to flourish, then effectively the only way they can do so is by intervening early in the communication cycle. Building up, before specific contentious issues arise, an atmosphere of communication and trust between experts and stakeholders.

\section{Conclusion}

This paper has argued that functional foods are at this time an ill-defined and potentially confusing development area in our understanding of, and support for, better public nutrition. The confusion arises from a number of sources, 
including problems of definition, distinction from similar concepts, such as health foods, and the different but interdependent perspectives of the main stakeholder groups. A real possibility is that this lack of clarity provides a seed bed in which public fears may grow.

It is important to be aware of the public's reaction to risks, how it can arise and develop independently of scientific evidence, and its potential for significantly worsening the regulatory environment within which developments in functional foods have to take place. For this new food sector to emerge fully into the consumer consciousness and to survive it needs positive media coverage and the acceptance of consumers, nutritionists and the medical community ${ }^{6}$. Important challenges for the different stakeholders involved are corporately to improve communication, education and perceptions, particularly of consumers, with regard to functional foods.

Mandatory rather than voluntary legislation could help clarify the issue of definition of functional foods. Scientific criteria for health claims for functional foods are considered essential if society is to receive the full advantage from the potential public health benefits that science and technology can provide ${ }^{40}$ and also to protect consumers from being misled and deceived. The preventive aspect of nutrition gave birth to the concept of functional foods ${ }^{34}$ and it is therefore important that caution is exercised in the development of this food sector.

To encourage positive consumer interest, functional foods should be presented as natural products that are part of a broader, healthier lifestyle and $\operatorname{diet}^{6}$. Communication of the proposed health benefits of functional foods to consumers, through intermediaries such as the different stakeholders involved, can promote public health and the development of functional food research ${ }^{41}$. The main priorities of the stakeholders involved should therefore be the protection and education of the consumer.

\section{References}

1 Wrick KL. Consumer issues and expectations for functional foods. Crit. Rev. Food Sci. Nutr. 1995; 35: 167-73.

2 Hardy G. Nutraceuticals and functional foods: introduction and meaning. Nutrition 2000; 16: 688-9.

3 Roberfroid MB. Concepts and strategy of functional food science: the European perspective. Am. J. Clin. Nutr. 2000; 71: $1660 S-4 S$.

4 Schenker S. Functional foods: key facts. Food Sci. Technol. Today 1999; 13: 194-6.

5 Blades M. Functional foods or nutraceuticals. Nutr. Food Sci. 2000 30: 73-5.

6 Mintel International Group Limited. Functional Foods. London: Mintel International Group Limited, 2000.

7 Winkler J. Functional foods: the challenges for consumer policy. Consumer Policy Rev. 1996; 6: 210-4.

8 Roberfroid MB. A European consensus of scientific concepts of functional foods. Nutrition 2000; 16: 689-91.

9 Huggett AC, Verschuren PM. The safety assurance of functional foods. Nutr. Rev. 1996; 54: S132-40.

10 Arens U. Food Fortification. London: The British Nutrition Foundation, 1994.
11 National Food Authority. Functional Foods: Policy Discussion Paper. Canberra, Australia: National Food Authority, 1994.

12 Richardson DP. Functional foods - shades of gray: an industry perspective. Nutr. Rev. 1996; 54: S189-94.

13 Young J, Rayner M, Winkler JT, Richardson DP. Regulatory and consumer issues. In: Sadler M, Saltmarsh M, eds. Functional Foods: the Consumer, the Product and the Evidence. Cambridge: Royal Society of Chemistry, 1998; $167-211$.

14 Brug J, Riedstra M, Pruyn JF, Iowick MRH. Effecten van derde landelijke Let op Ver Campagne [Effects of Third World campaign: be aware of your fat intake]. Voeding 1993; 57 : $8-10$.

15 Silverglade BA, Heller IR. Are functional foods the solution to dysfunctional diets? A review of US regulatory requirements and lessons from abroad. Food Drug Law J. 1997; 52: 313-21.

16 Hiliam M. Functional foods: the Western consumer viewpoint. Nutr. Rev. 1996; 54: S189-94.

17 Childs MN, Poryzees GH. Foods that help prevent disease: consumer attitudes and public policy implications. Br. Food J. 1998; 100: 419-26.

18 Wrick KL. The potential role of functional foods in medicine and public health. In: Goldberg I, ed. Functional Foods. New York: Chapman \& Hall, 1994.

19 Kirk S, Cade J, Barrett J, Conner M. Diet and lifestyle characteristics associated with dietary supplement use in women. Public Health Nutr. 1999; 2: 69-73.

20 Kirk S, Woodhouse A, Conner M, and the UKWCS Steering Group. Beliefs, attitudes and behaviour in relation to supplement use in the UK Women's Cohort Study. Proc. Nutr. Soc. 1998; 57: 54A.

21 James WP, Nelson M, Ralph A, Leather S. Socioeconomic determinants of health. The contribution of nutrition to inequalities in health [see comments]. BMJ 1997; 314: 1545-9.

22 Cade J, Upmeier H, Calvert C, Greenwood D. Costs of a healthy diet: analysis from the UK Women's Cohort Study. Public Health Nutr. 1999; 2: 505-12.

23 Malaspina A. Functional foods: overview and introduction. Nutr. Rev. 1996; 54: S4-5.

24 Milner JA. Functional foods and health promotion. J. Nutr. 1999; 129: 1395S-7S.

25 Morris SE, Lean ME, Hankey CR, Hunter C. Who gets what treatment for obesity? A survey of GPs in Scotland. Eur. J. Clin. Nutr. 1999; 53(Suppl. 2): S44-8.

26 Truswell AS. Family physicians and patients: is effective nutrition interaction possible? Am. J. Clin. Nutr. 2000; 71: 6-12.

27 Randell A, Race J. Regulatory and legal aspects of functional foods: an international perspective. Nutr. Rev. 1996; 54: S152-5.

28 Jacobson MF, Silverglade B. Functional foods: health boon or quackery? [editorial]. BMJ 1999; 319: 205-6.

29 Ruffell M. UK health claims watchdog starts to bark: Joint Health Claims Initiative (JHCI) up and running. BNF Nutr. Bull. 2001; 26: 59-60.

30 Ashwell M. Functional foods: a simple scheme for establishing the scientific validity for all claims. Public Health Nutr. 2001; 4: 859-62.

31 Silverglade B, Jacobson MF. Functional foods: public health boon or 21st century quackery? CSPI Reports, 1999 [Online]. Available at http://www.cspinet.org/reports/functional_ foods_sum.htm (accessed 29 October 2001).

32 Hasler CM. Functional foods: the Western perspective. Nutr. Rev. 1996; 54: S6-10.

33 Law J. When is food a food and when is it a medicine? Scrip Mag. 1998 [Online]. Available at http://www.fimdefelice. org/clip.script998.html (accessed 26 July 2001). 
34 Pascal G. Functional foods in the European Union. Nutr. Rev. 1996; 54: S29-32.

35 Yardley K, Wright G, Pearman A. Survey: the social construction of risk aversion. Risk Decision Policy 1997; 2: 87-100.

36 Mazur L. Food companies need to listen to their consumers. Marketing 27 April 2000; 16.

37 Kunreuther H, Slovic P. Science, values and risk. Ann. Am. Acad. Political Social Sci. 1996; 545: 116-25.

38 Solvic P, Fischhoff B, Lichtenstein S. Facts and fears: understanding perceived risk. In: Schwing RC, Albers WA, eds. Societal Risk Assessment: How Safe Is Safe Enough? London: Plenum Press, 1980.

39 Kasperson R, Kasperson JX. The social amplification and attenuation of risk. Ann. Am. Acad. Political Social Sci. 1996; 545: 95-105.

40 Coletta FA. Road map for functional foods: central challenge and major priorities. Nutrition Today 1999 [Online]. Available at http://www.findarticles.com/cf_0/m0841/ 4_34/55764656/print.jttml (accessed 4 September 2000).

41 Diplock AT, Aggett PJ, Ashwell M, Bornet F, Fern EB, Roberfroid MB. Scientific concepts of functional foods in Europe: consensus document. Br. J. Nutr. 1999; 81: S1-27. 